\title{
Status of Thermal NDT of Space Shuttle Materials at NASA
}

\author{
K. Elliott Cramer ${ }^{\mathrm{a}}$, William P. Winfree ${ }^{\mathrm{a}}$, Kenneth Hodges ${ }^{\mathrm{b}}$, Ajay Koshti ${ }^{\mathrm{b}}$, Daniel Ryan ${ }^{\mathrm{c}}$ and Walter \\ W. Reinhardt ${ }^{\mathrm{d}}$ \\ ${ }^{a}$ NASA Langley Research Center, MS 231, Hampton, VA 23681-2199 \\ ${ }^{b}$ NASA Johnson Space Center, 2101 NASA Parkway, ES4, Houston, TX 77058 \\ 'USA NDE, United Space Alliance, LLC, 8550 Astronaut Blvd. USK-823 Hangar N, Cape \\ Canaveral, FL 32920 \\ ${ }^{\mathrm{d} N D E}$ Group, H022-F152, The Boeing Company, 5301 Bolsa Ave., Huntington Beach, CA 92647
}

\begin{abstract}
Since the Space Shuttle Columbia accident, NASA has focused on improving advanced NDE techniques for the Reinforced Carbon-Carbon (RCC) panels that comprise the orbiter's wing leading edge and nose cap. Various nondestructive inspection techniques have been used in the examination of the RCC, but thermography has emerged as an effective inspection alternative to more traditional methods. Thermography is a non-contact inspection method as compared to ultrasonic techniques which typically require the use of a coupling medium between the transducer and material. Like radiographic techniques, thermography can inspect large areas, but has the advantage of minimal safety concerns and the ability for single-sided measurements.
\end{abstract}

Details of the analysis technique that has been developed to allow insitu inspection of a majority of shuttle RCC components is discussed. Additionally, validation testing, performed to quantify the performance of the system, will be discussed. Finally, the results of applying this technology to the Space Shuttle Discovery after its return from the STS-114 mission in July 2005 are discussed.

Keywords: thermography, reinforced carbon-carbon

\section{INTRODUCTION}

The space shuttle's thermal protection system is made from materials that can perform at temperatures up to $1650^{\circ} \mathrm{C}$. Reinforced Carbon-Carbon (RCC) is used in areas where temperatures exceed $1275^{\circ} \mathrm{C}$, such as at the wing leading edges, nose cap, and chin panel. It is made from layers of rayon cloth graphitized and impregnated with a phenolic resin and coated with silicon-carbide. Locations on the orbiter that experience temperatures below $1275^{\circ} \mathrm{C}$ are protected with black tiles made from low-density, high-purity silica amorphous fiber insulation. These hightemperature reusable surface insulation tiles (HRSI) are found on the underside of the vehicle. Additionally, lowertemperature reusable surface insulation white tiles (LRSI) are used in areas of the fuselage where temperatures do not exceed $650^{\circ} \mathrm{C}$. These tiles differ from their black counterparts in that they are thinner ${ }^{1,2}$. Figure 1 shows the location of these materials on the orbiter.

To satisfy the first recommendation of the Columbia Accident Investigation Board, NASA investigated numerous nondestructive evaluation (NDE) methods for certifying the integrity of the orbiter's wing leading edge RCC materials ${ }^{3}$. Among the NDE methods investigated for use on the RCC materials were advanced digital radiography, high resolution computed tomography, thermography, advanced ultrasound, and advanced eddy current systems. Ultimately, NASA selected thermography as the first inspection step for RCC panels. A full inspection of all RCC materials on the obiter will be conducted between each flight. Thermography's advantages are that it is a fast, noncontacting, one-sided application, easy to implement in the orbiter's servicing environment, and it detects the critical flaws of interest. 


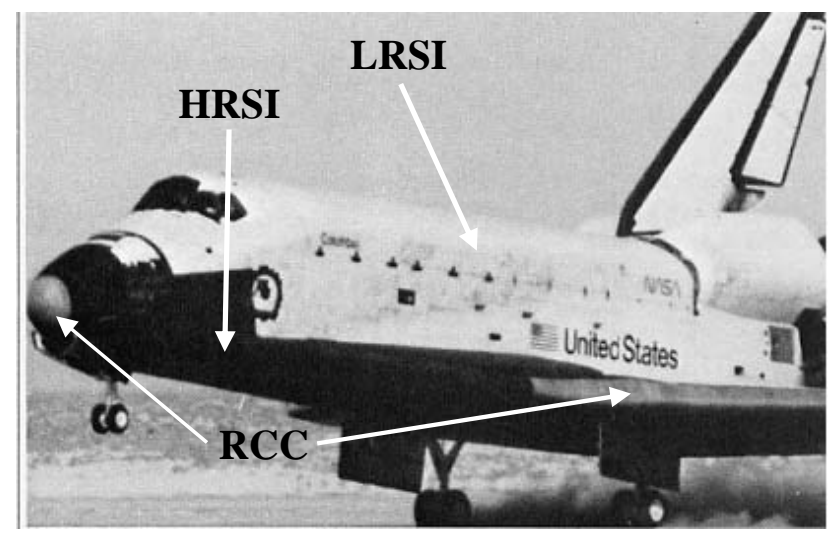

Figure 1 - Locations of the RCC, HRSI, and LRSI components of the thermal protection system on the orbiter.

\section{EXPERIMENTAL EQUIPMENT}

The experimental equipment that has been developed for performing inspection of the RCC panels in the Orbiter Processing Facility (OPF) at Kennedy Space Center (KSC) consists of the flash thermal inspection system and a mechanical positioning system.

\section{a. Thermal Inspection System}

The flash thermography system for this inspection is the commercially available Echotherm ${ }^{\circledR}$ system from Thermal Wave Imaging (TWI). The system features one of two hoods, both containing a 320 × 256 Phoenix ${ }^{\circledR}$ infrared (IR) camera with two 4800-Joule xenon photographic flash tubes. The first hood is a "straight" hood typically provided with the commercial system. This hood (shown in figure 2a) has dimensions of $36.8 \mathrm{~cm}$ wide by $26.7 \mathrm{~cm}$ deep by 40.6 $\mathrm{cm}$ tall and is configured such that the IR camera views the inspection surface directly. When the Phoenix ${ }^{\circledR}$ camera is added to the back of the flash hood the total height of the inspection system (maximum clearance needed from the inspection surface) is increased to $71.1 \mathrm{~cm}$. The flash of the "straight" hood produces a flash energy density of 7.15 joules per square centimeter at the mouth of the hood. This was calculated from the final temperature increase of a $0.635 \mathrm{~cm}$ thick sample of RCC and the nominal thermal properties of RCC. The flash of the "straight" hood flash lamps provides a uniform illumination within $10 \%$ across an area of $24.8 \mathrm{~cm}$ x $32.7 \mathrm{~cm}$ of a flat reference standard at the mouth of the hood as determined from measurements of the temperature rise of the RCC material.

Because of OPF clearance limitations it is necessary to have a custom "right angle" hood built to accommodate insitu inspection of the orbiter wings. The "right angle" hood (shown in figure $2 \mathrm{~b}$ ) has dimensions of $43.2 \mathrm{~cm}$ wide by 36.8 $\mathrm{cm}$ deep by $34.3 \mathrm{~cm}$ tall and is configured such that heating and imaging of the inspection surface is accomplished by reflecting off a mirror mounted at $45^{\circ}$ to the surface. The "right angle" hood produces a flash energy density of 6.0 joules per square centimeter at the mouth of the hood. This was calculated from the final temperature increase of a $0.635 \mathrm{~cm}$ thick sample of RCC and the nominal thermal properties of RCC. The flash of the "straight" hood flash lamps provides a uniform illumination of within $7.3 \%$ across an area of $24.8 \mathrm{~cm} \mathrm{x} 32.4 \mathrm{~cm}$ of a flat reference standard at the mouth of the hood as determined from measurements of the temperature rise of the RCC material.

The hoods are connected to a base station which houses the system computer and power sources for the various components. Thermographic inspection is accomplished by placing the hood on the section of material to be inspected. The bottom of the hood completely surrounds or sits atop the material, depending on the dimension of the specimen. The flash lamps are be triggered either by operator controls on the hood or by the computer. Thermographic images of the specimen are captured by the Phoenix ${ }^{\circledR}$ infrared camera for a predetermined amount of time and stored in the computer for further analysis. The camera's noise equivalent temperature difference, cited by the manufacturer, is $0.025^{\circ} \mathrm{C}$ operating the detector array in the 3 to 5 micrometer wavelength range. External optics, consisting of a wide-angle lens, using germanium optical elements, increases the system field-of-view by a factor of approximately two. The expanded field-of-view of this lens is $41^{\circ}$ horizontally and $31^{\circ}$ vertically. 


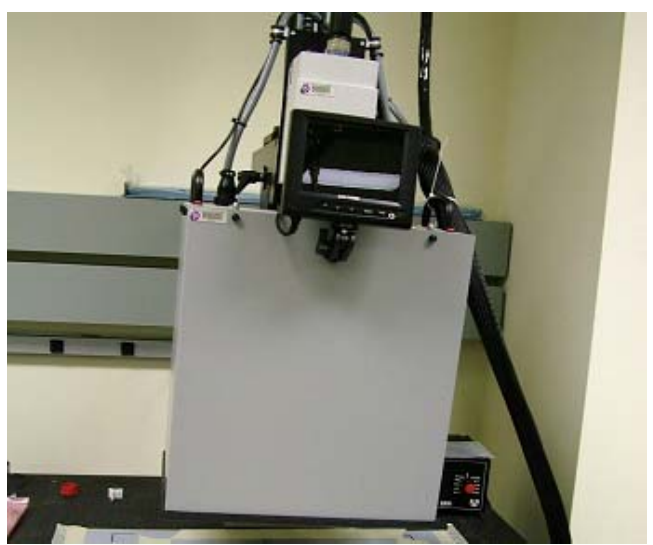

(a)

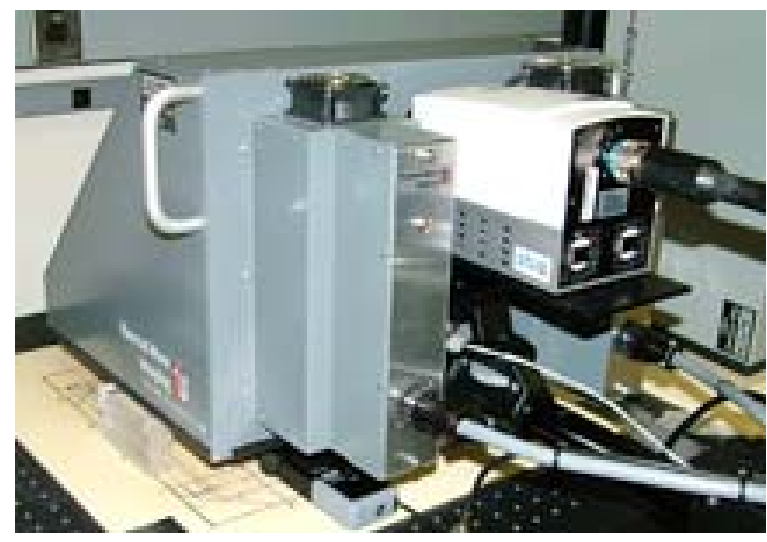

(b)

Figure 2 - Photographs of the two hoods used with the EchoTherm ${ }^{\circledR}$ thermography system. (a) "Straight" hood and (b) "Right angle" hood.

\section{b. Positioning System}

The positioning system was developed by Oceaneering Space Systems, Inc. to allow easy movement and positioning of the camera/hood assembly of the EchoTherm ${ }^{\circledR}$ around both wings and the nose cap of the Space Shuttle. The positioning system consists of an articulated arm manufactured by Strongarm ${ }^{\circledR}$, Inc. which has been mounted to a lift table that can be moved around the orbiter. The lift table can be locked into place by securing it to a rail system attached to the decking in the OPF. Figure 3 shows a schematic of the positioning system.

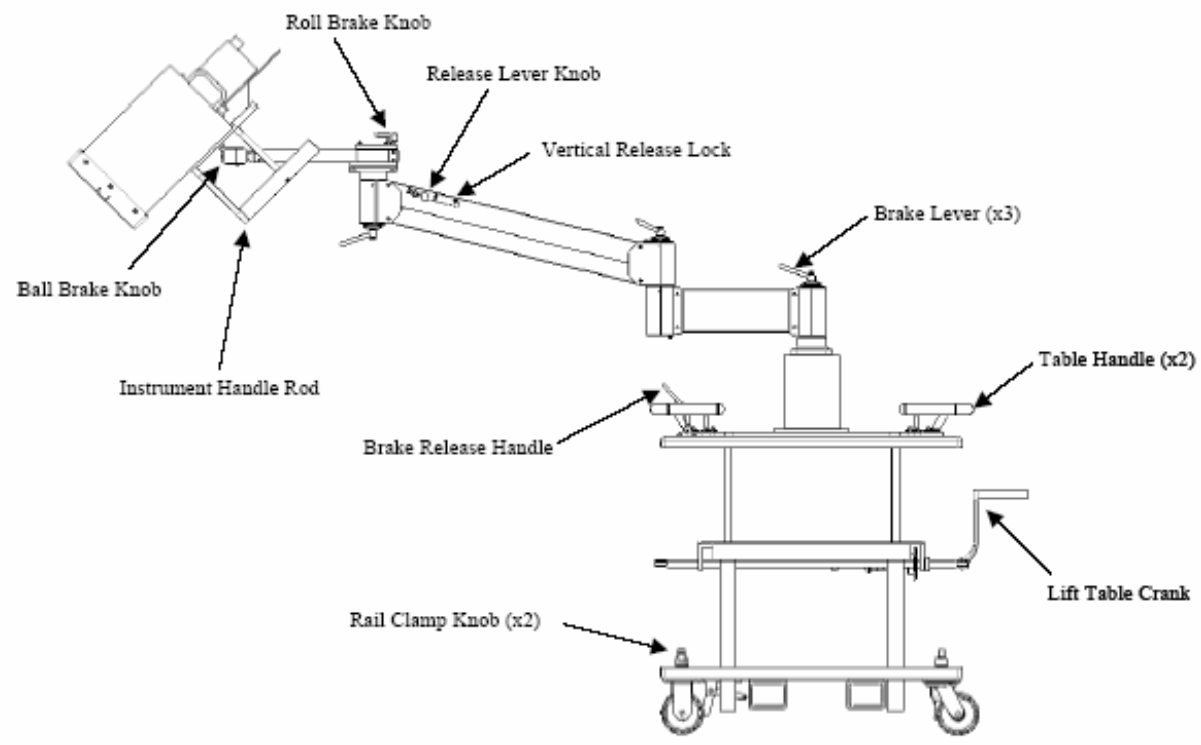

Figure 3 - Schematic of the lift table and articulated arm assembly that is used to move the camera/hood assembly around the orbiter in the OPF. 


\section{DATA ANALYSIS}

Principal Component Analysis (PCA) is a common data reduction methodology applied to thermal NDE data. The algorithm is based on the decomposition of the thermal data into its principal components or eigenvectors using singular value decomposition (SVD) ${ }^{4-7}$ PCA is performed by first reformatting the three-dimensional thermal data into a two-dimensional array where the columns contain the spatial information and the rows contain the temporal information such that $T(x, y, t)$ becomes $A(n, m)$ where $n=N_{x} * N_{y}$ and $m=N_{t}$, where $N$ indicates the number of elements in a given direction. The matrix $\mathrm{A}$ is then modified by subtracting the mean along the time dimension, and decomposed to yield the eigenvalues and eigenvectors:

$$
\mathrm{A}=\mathrm{U} \Gamma \mathrm{V}^{\mathrm{T}}
$$

where $\mathrm{U}$ and $\mathrm{V}$ are orthogonal matrices with columns that form the eigenvectors of $\mathrm{AA}^{\mathrm{T}}$ and $\mathrm{A}^{\mathrm{T}} \mathrm{A}$ respectively and $\Gamma$ contains the singular values (the nonnegative square roots of the eigenvalues) of $\mathrm{A}^{\mathrm{T}} \mathrm{A}$ or $\mathrm{AA}^{\mathrm{T}}$. Since the columns of $\mathrm{U}$ corresponding to nonzero singular values, form an orthogonal basis for the range space of $\mathrm{A}$, the entire thermal data set can be described by this basis. Because thermal NDE signals are well behaved and slowly varying in time, the predominant temporal variations of the entire data set are usually contained in the first or second eigenvector. The PCA images are formed by calculating the dot product of the measured temperature response, pixel by pixel, with the eigenvectors of interest (usually the two associated with the largest eigenvalues). Defects in RCC material change the local temporal variation of the data and thus appear as either light or dark regions in the PCA images.

While this process is quite effective in reducing thermal data, the SVD can be computationally intense especially with the very large three-dimensional arrays of thermal data typically produced in the inspection of RCC. To reduce the required computation and improve the reproducibility of the analysis, for this application the PCA reduction is performed using a set of eigenvectors generated from data acquired on multiple RCC data sets.

\section{VALIDATION OF THE DATA}

The primary specimen used for validation was a $15 \mathrm{~cm}$ square RCC specimen with 18 flat-bottom holes at five varying diameters and depths. Figure 4 illustrates the size, depth, and location of the holes as observed from the back side of the sample. The depths of the defects ranged from material loss only in the silicon carbide layer (row E in figure 4) to holes $75 \%$ through the full thickness of the sample (row A). Flash thermography was performed on this specimen using the EchoTherm ${ }^{\circledR}$ system. Data was collected at a frame rate of 60 frames per second for 14 seconds after the flash heating. Figure 5 shows the typical results obtained with PCA processing of the thermal data. The four images displayed were obtained by projecting the thermal data onto the first two fixed, experimental eigenvectors in two different time windows, $0.16-3.5$ seconds after the flash (figure $5 \mathrm{a}$ and $5 \mathrm{~b}$ ) and $1-11.5$ seconds after the flash (figure $5 \mathrm{c}$ and $5 \mathrm{~d}$ ). In addition to the flat-bottom hole specimen other test articles were created by impacting the surface of the RCC with various projectiles at different velocities. Figure 6 shows the results obtained on one of these impact specimens. Figure $6 \mathrm{a}$ is a visible photograph of the impact surface, figure $6 \mathrm{~b}$ shows the PCA processed thermal results, where the projection onto the $1^{\text {st }}$ eigenvector of the late time window is displayed (this is comparable to figure $5 \mathrm{c}$ ). Finally, figure $6 \mathrm{c}$ is an ultrasonic c-scan image of the specimen.

Final validation of the complete system (Thermal Inspection System coupled to the Manipulator System) was performed at Oceaneering Space Systems, Inc. facility in Friendswood, Texas. Testing was performed on one full scale RCC wing leading edge Panel $11 \mathrm{~L}$ and one mating tee-seal $11 \mathrm{~L}$. The panel and tee-seal were mounted on a test fixture to simulate the hardware as installed on the Orbiter, and a series of flat-bottom hole defects of different sizes and depths were drilled into the panel. The location of the defects was masked from the inspectors during data acquisition and analysis. Data acquisition was performed with the TWI EchoTherm ${ }^{\circledR}$ inspection system using both the "straight" and "right angle" flash hoods. The raw data acquired by the TWI system was then processed using PCA with a fixed set of eigenvectors. The thermography principal investigator for this project used the processed data to locate and size all defects. This information was provided to Boeing, Huntington Beach personnel for comparison with the manufactured defect maps. Figure 7 shows the system set up to perform the inspection during validation. 


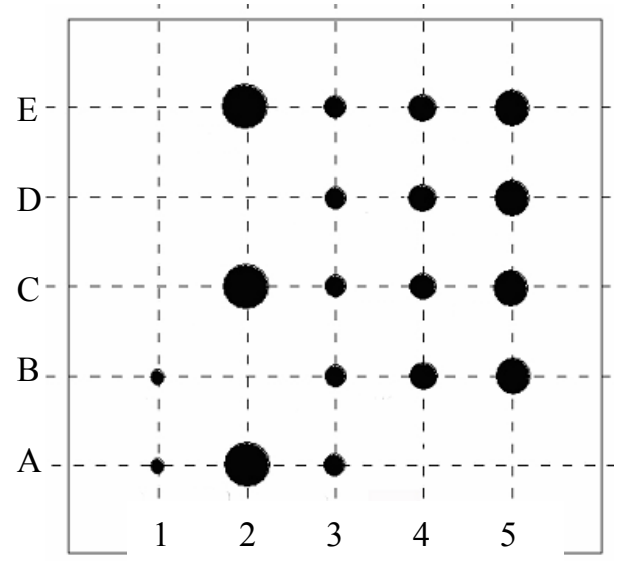

\begin{tabular}{|c|c|}
\hline Row Number & Depth of Flaw \\
\hline A & $88 \%$ \\
\hline B & $72 \%$ \\
\hline C & $48 \%$ \\
\hline D & $24 \%$ \\
\hline Column Number & $12 \%$ \\
\hline 1 & Diameter of Flaw \\
\hline 2 & $0.318 \mathrm{~cm}$ \\
\hline 3 & $1.27 \mathrm{~cm}$ \\
\hline 4 & $0.635 \mathrm{~cm}$ \\
\hline 5 & $0.476 \mathrm{~cm}$ \\
\hline
\end{tabular}

Figure 4 - Drawing of RCC flat-bottom hole specimen and table of flaw diameters and flaw depths as a fraction of the total specimen thickness as provided by the manufacturer of the specimen.

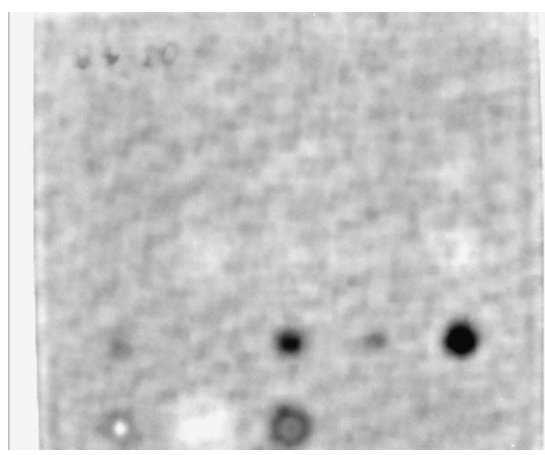

(a)

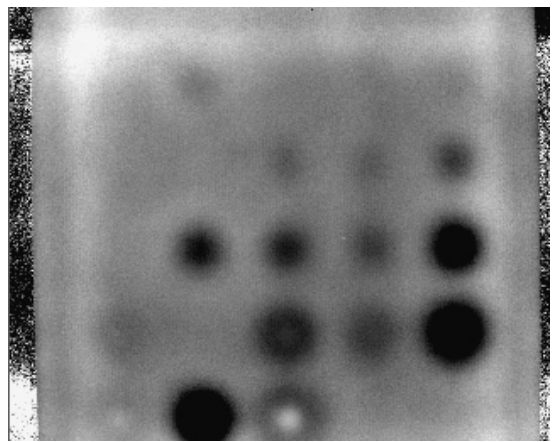

(c)

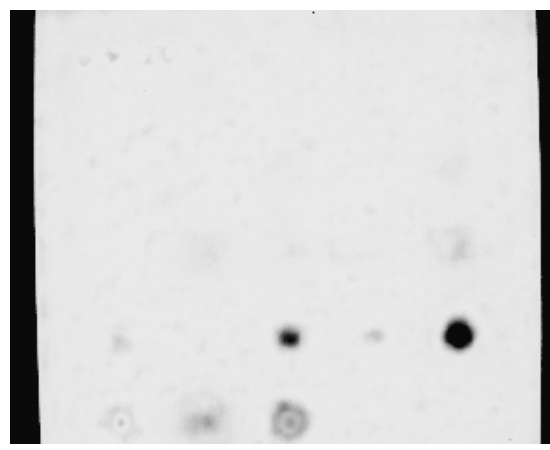

(b)

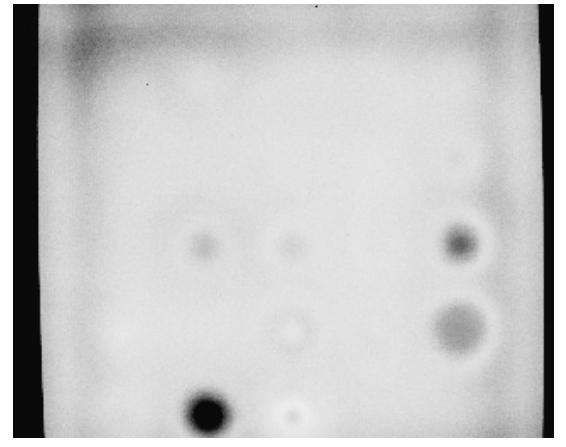

(d)

Figure 5 - First (a) and second (b) projection of early time window PCA images of RCC flat-bottom hole specimen processed fixed eigenvectors. First (c) and second (d) projection late time window PCA images of RCC flat-bottom hole specimen processed with fixed eigenvectors. 


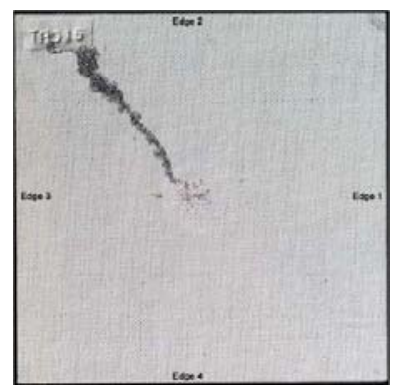

(a)

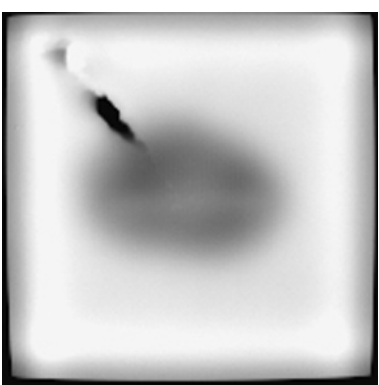

(b)

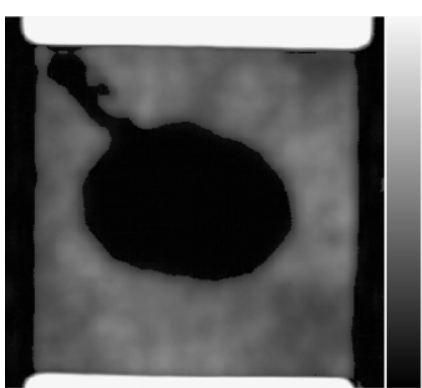

(c)

Figure 6 - Results of thermal inspection with PCA processing for a $15 \mathrm{~cm}$ square RCC specimen impacted on the inspection surface with a projectile at 626 meters per second. (a) Photograph of surface after impact, (b) first projection late time thermal image and (c) ultrasonic pulse echo image of specimen.

Figures 8 and 9 present graphs of the diameter of defect verses the depth of that defect for all defects. The defects detected are shown as solid circles; those not detected are shown as solid squares. Additionally, the required detection envelope is indicated by the solid line and given by the equation:

$$
\mathrm{D}=2.8 * \mathrm{~d}+0.042,
$$

where $\mathrm{D}$ is the diameter of the defect and $\mathrm{d}$ is the depth. The dashed line is the experimentally determined detection envelope. This testing indicates the system is able to detect flat-bottom hole defects in this structure with the required accuracy of 100\% (28 of 28 required defects) for the "straight" hood and 96.4\% (27 of 28 required defects) for the "right angle" hood.

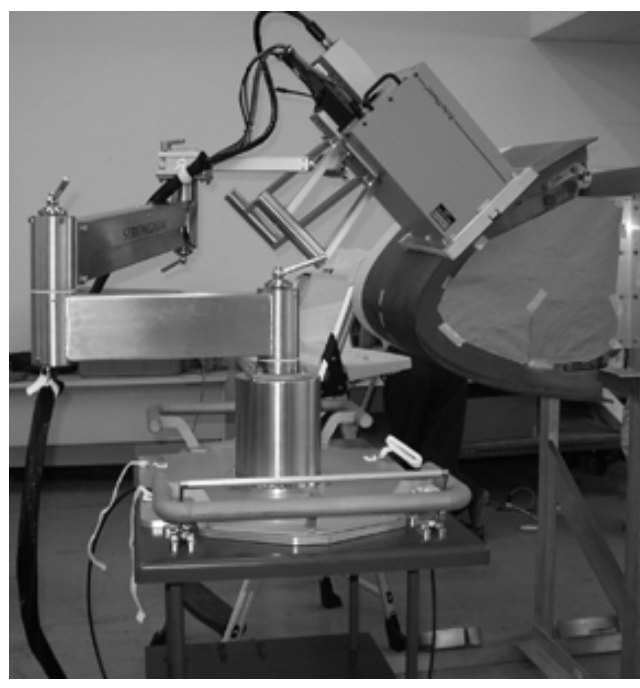

(a)

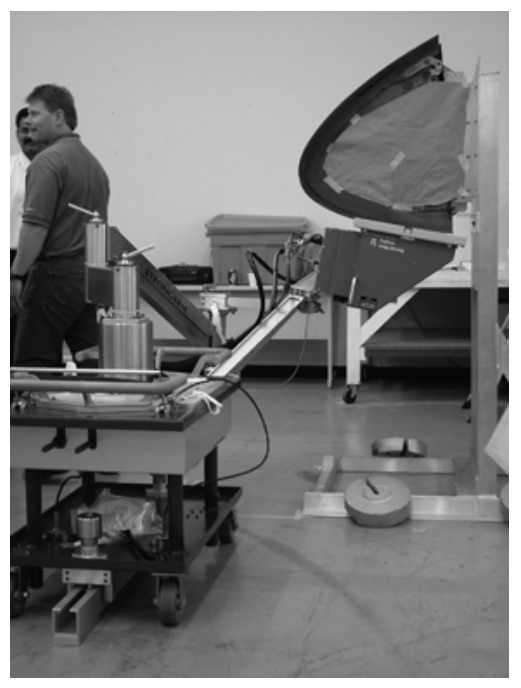

(b)

Figure 7 - Photographs of both the (a) "straight" and the (b) "right angle" hoods performing the validation inspection on RCC wing leading edge Panel 11L. 


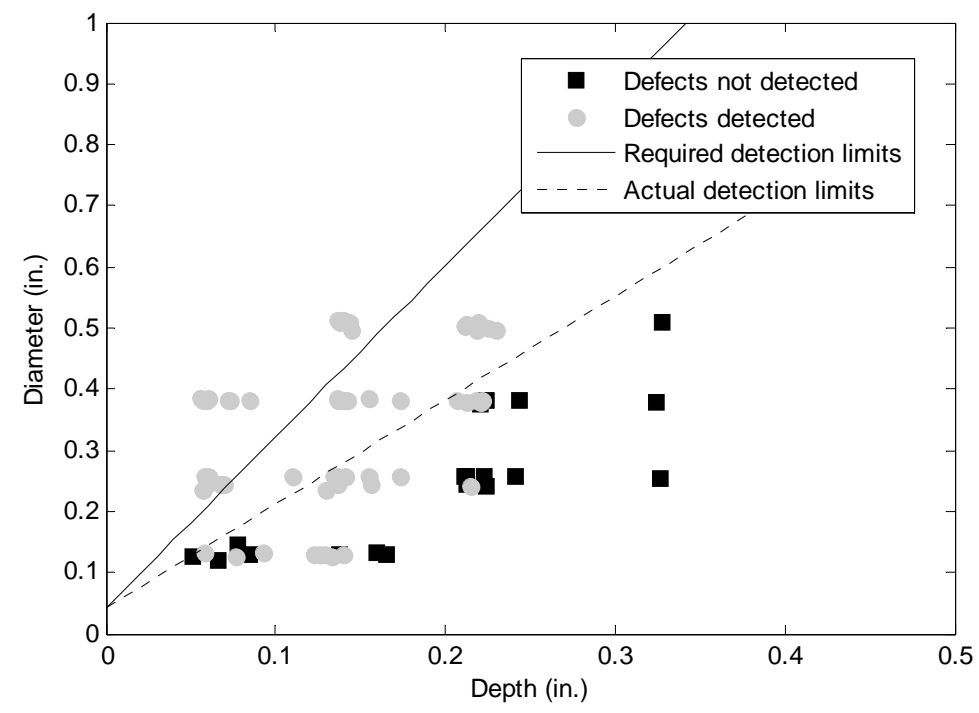

Figure 8 - Results for detection of flat-bottom holes in RCC material using the "straight" hood configuration.

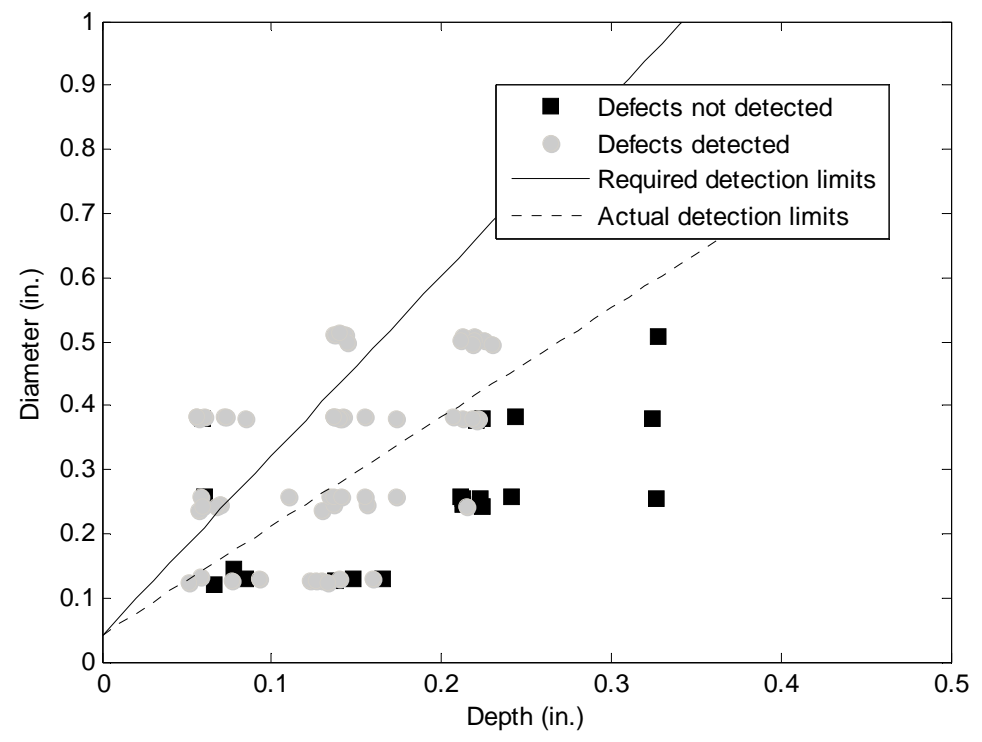

Figure 9 - Performance results for detection of flat-bottom holes in RCC material using the "right angle" hood configuration.

\section{ORBITER INSPECTION RESULTS}

The complete thermography system was applied to the Space Shuttle Discovery upon its return from flight STS-114 in August of 2005. Figure 10 shows the system deployed in the OPF performing an inspection on the left wing RCC material. Figure 11 shows the results obtained during the inspection process. The image shown in figure 11a is a photograph of the inspection region with a suspect area pointed to by an NDE technician. The PCA processed thermal image shown in figure $11 \mathrm{~b}$ shows the indication consistent with damaged RCC material. 


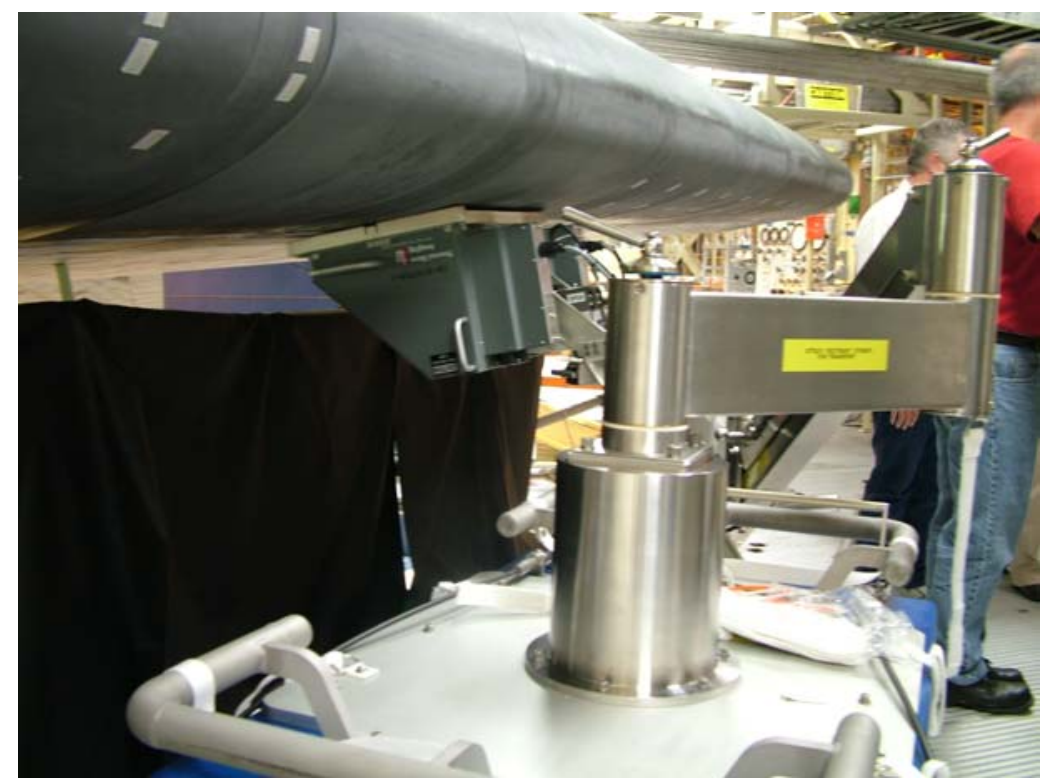

Figure 10 - Photograph of the manipulator system and the "right angle" hood/camera assembly performing an inspection in the OPF at KSC on the Space Shuttle Discovery following STS-114.

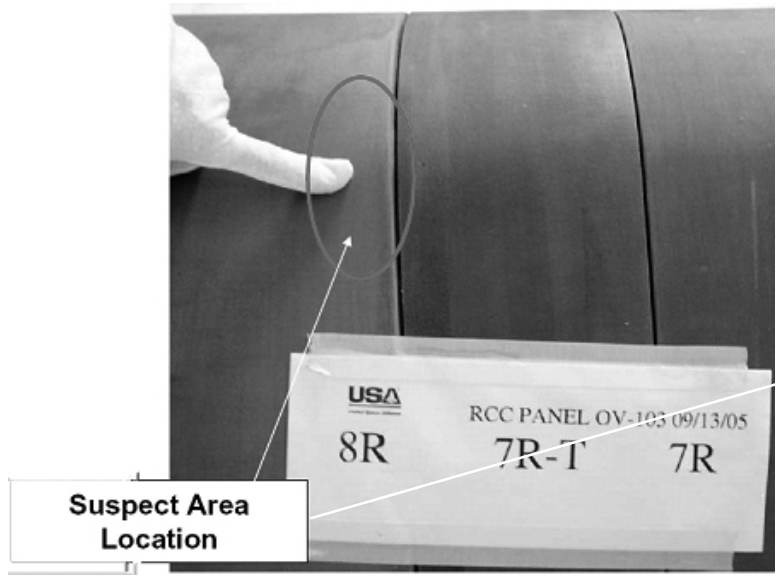

(a)

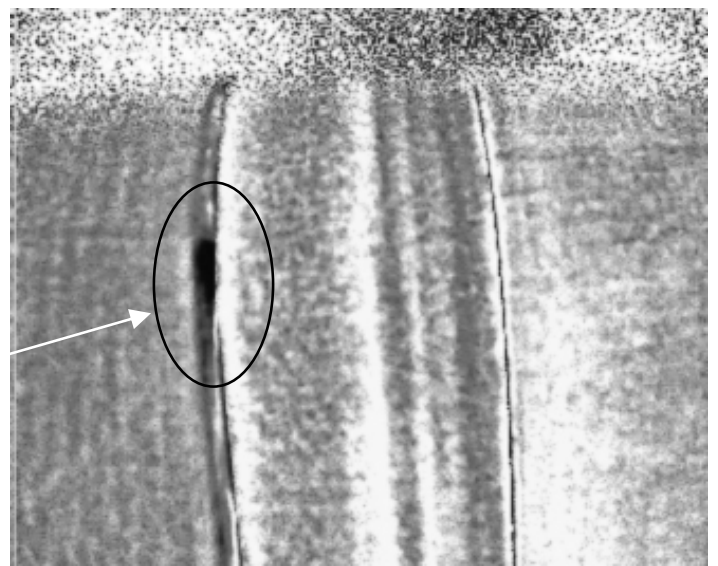

(b)

Figure 11 - Typical results of the thermal inspections performed on Discovery. (a) Shows a photograph of the inspection area with a suspect location indicated. (b) PCA processed thermal image of the same area also showing the suspect damage region.

\section{CONCLUSIONS}

The validation testing confirmed the ability of the Thermal Wave Imaging System coupled with the PCA processing to detect flat-bottom hole defects in RCC wing leading edge structure within the required detection envelope with $100 \%$ accuracy ( 28 of 28 required defects) for the straight hood and with $96.4 \%$ accuracy ( 27 of 28 required defects) for the right angle hood. Beginning in August 2005 this system has been successfully deployed into the OPF at KSC and has been used for the inspection of both the wings and nose cap of the Space Shuttle Discovery following STS-114. 


\section{REFERENCES}

1. Kerry Mark Joels and Gregory P. Kennedy, The Space Shuttle Operator's Manual (Ballantine Books, New York, 1982).

2. "Space Shuttle Orbiter Systems," as reported on science.ksc.nasa.gov/shuttle/technology/sts-newsref/sts_sys.html.

3. H. W. Gehman, et al, "Columbia Accident Investigation Board," Report Volume 1, U.S. Government Printing Office, Washington, DC, August 2003.

4. N. Rajic, "Principal component thermography for flaw contrast enhancement and flaw depth characterisation in composite structures", Composite Structures, Vol. 58, pp. 521-528, 2002.

5. N. Rajic "Principal Component Thermography," DSTO-TR-1298, 2002.

6. W.P. Winfree and J.N. Zalameda, "Thermographic determination of delamination depth in composites", Proc. SPIE Vol. 5073, pp. 363-373, Thermosense XXV, K. Elliott Cramer, Xavier P. Maldague; Eds., 2003.

7. J.N. Zalameda, P.A. Howell and W.P. Winfree, "Compression techniques for improved algorithm computational performance", Proc. SPIE Vol. 5782, pp. 399-406, Thermosense XXVII, G. Raymond Peacock, Douglas D. Burleigh, Jonathan J. Miles; Eds., 2005. 